\title{
Social protection and climate change
}

\section{emerging issues for research, policy and practice}

Johnson, Craig; Bansha Dulal, Hari; Prowse, Martin Philip; Krishnamurthy, Krishna; Mitchell, Tom

Published in:

Development Policy Review

DOI:

10.1111/dpr.12036

Publication date:

2013

Document version

Peer reviewed version

Citation for published version (APA):

Johnson, C., Bansha Dulal, H., Prowse, M. P., Krishnamurthy, K., \& Mitchell, T. (2013). Social protection and climate change: emerging issues for research, policy and practice. Development Policy Review, 31(Suppl. s2), o2-o18. https://doi.org/10.1111/dpr.12036 


\section{Social Protection and Climate Change: Emerging Issues for Research, Policy and Practice}

\section{Craig Johnson, Hari Bansha Dulal, Martin Prowse, Krishna Krishnamurthy and Tom Mitchell*}

This article lays the foundation for this special issue on social protection and climate change, introducing and evaluating the ways in which the individual articles contribute to our understanding of the subject.

Key words: Livelihoods, vulnerability, climate change, social protection, cash transfers, asset transfers, livelihood diversification

\section{An emerging research agenda}

Donors and researchers have become increasingly interested in the idea of using asset transfers, cash transfers and other forms of 'social protection' to reduce poverty and vulnerability to climate change (for example, Davies et al., 2008; Tanner et al., 2009; Johnson and Krishnamurthy, 2010; Béné, 2011; Wood, 2011; Kuriakose et al., this volume). Social protection (SP) has been shown to provide an important means of reducing vulnerability to climate-induced poverty spirals during periods of acute environmental stress (Awokuse, 2011; Béné, 2011; Devereux, 2009; Devereux and Sabates-Wheeler, 2004; Doocy et al., 2006; Heltberg et al., 2009; Johnson and Krishnamurthy, 2010; Todd et al., 2010; Maluccio, 2010; Sabates-Wheeler and Devereux, 2007; 2010; Wood, 2011; NiñoZarazua et al., 2012). Correspondingly, many donors now use cash- and asset-transfer programmes to build and supplement the incomes, assets and livelihoods of vulnerable populations (Niño-Zarazua et al., 2012). Similarly, many countries have introduced a wide range of policies aimed at providing regular and reliable assistance in the form of cash for work, vulnerable feeding programmes and employment guarantees (ibid.). ${ }^{1}$

At the heart of the SP model is an assumption that the failure to meet basic needs (of nutrition, healthcare, etc.) during droughts, famines and other volatile periods results from a loss or devaluation of skills, assets and incomes in relation to the cost of food, shelter and other basic entitlements. The perceived solution is therefore to provide affected populations with asset and cash transfers that can theoretically improve their ability to build livelihoods

*Respectively, University of Guelph, Canada (cjohns06@uoguelph.ca); World Food Programme, Rome; University of Copenhagen, Denmark, and University of Antwerp, Belgium; World Bank, Washington, DC; and Overseas Development Institute, London.

1. Donor interest in SP reflects a number of trends that have been emerging over the last 10 to 15 years. One is a commitment on the part of many donors to untie food aid in the context of international development assistance and humanitarian relief (Awokuse, 2011). A second is a growing recognition that famine and other threats to food security are a function of 'production, exchange and response' failures (Devereux, 2009) that undermine the ability of poor and vulnerable groups to command entitlements in volatile market settings. A third is a shift away from emergency aid in favour of more regular and reliable forms of social assistance (Devereux, 2009; Awokuse, 2011; Niño-Zarazua et al., 2012). 
and 'command' scarce resources in volatile market settings (Awokuse, 2011; Béné, 2011; Devereux, 2009; Devereux and Sabates-Wheeler, 2004; Sabates-Wheeler and Devereux, 2007; 2010; Heltberg et al., 2009; Matin et al., 2008; Wood, 2011; Niño-Zarazua et al., 2012).

However, the ability of SP to build livelihoods and resilience in advance of longerterm climatic changes is still poorly understood, reflecting the fact that few (if any) SP programmes are explicitly designed to address the kinds of scenarios being described by the Intergovernmental Panel on Climate Change (IPCC) (Davies et al., 2008; Wood, 2011; Béné, 2011). Moreover, questions have been raised about the ability of asset and cash transfers to address longer-term, inter-generational patterns of poverty and vulnerability to environmental change (Heltberg et al., 2009; Barrientos and Niño-Zarazua, 2010; Johnson and Krishnamurthy, 2010; Béné, 2011; Wood, 2011). Cash transfers, for instance, have been shown to provide an important means of preventing disaster-induced poverty spirals, but they are less effective at addressing the inter-generational factors contributing to risk, poverty and vulnerability (Devereux and Sabates-Wheeler, 2004; Doocy et al., 2006; Teichman, 2007; Sabates-Wheeler and Devereux, 2007; Heltberg et al., 2009; Barrientos and Niño-Zarazua, 2010; Johnson and Krishnamurthy, 2010; Wood, 2011; Niño-Zarazua et al., 2012). Similarly, crop and index-based insurance programmes provide an effective means of spreading risk and reducing losses due to flooding and drought, but they also often create strong incentives to invest in climate-sensitive crops (such as paddy) and regions (such as floodplains and river deltas), highlighting concerns about discounting and moral hazard (Heltberg et al., 2009; Wood, 2011; IPCC, 2012; Kuriakose et al., this volume; Panda, this volume).

Developing policies that can reduce poverty and vulnerability to climate change is a pressing global priority (Klein et al., 2007; Boyd et al., 2009; Brooks et al., 2009; Prowse et al., 2009; IPCC, 2012). This Special Issue of Development Policy Review explores the role that SP can play in this process. Drawing upon empirical field research from India and Bangladesh, and secondary data analysis from Ethiopia, it presents new findings that highlight the opportunities and challenges of using SP to build inter-generational resilience to climate change. Building upon the World Bank's recent background report on 'climate responsive social protection,' (Kuriakose et al., this volume), it identifies ways in which climate change can be incorporated into development policy and practice.

The volume starts from the premise that the climatic changes we may expect to see over the present century will entail transformations in rainfall, temperature and seasonality, the impact of which will be inconsistent with the strategies farmers, resource managers and policy-makers have traditionally used to sustain livelihoods in environmentally sensitive regions and sectors, such as farming, forestry and fishing (IPCC, 2012; Kuriakose et al., this volume; Box 1). According to the recent report of the Intergovernmental Panel on Climate Change on extreme climate events (Lavell et al., 2012), heat waves, heavy precipitation and droughts will become increasingly frequent over the course of this century. Such changes are expected to impose a heavy toll on developing countries, where agriculture, public health systems, food supplies, and human settlements are least able to adapt to extreme climate events such as flooding, windstorms, disease and drought (Parry et al., 2007; Lavell et al., 2012; Kuriakose et al., this volume).

This article proceeds as follows. First, it reviews the empirical literature on SP and environmental change, highlighting the particular ways in which SP policies have been 
used to influence coping and adaptation strategies in the context of rapid-onset disasters and long-term environmental change. Second, it situates its analysis within a broader policy context about the real and ideal relationship between long-term development policy and climate change, making the case that SP can play an important role in building the livelihoods and resilience of the poor if it is able to incorporate inter-generational decisions about discounting and investment into processes of evaluation and design. Finally, it identifies the methodological challenges of understanding and evaluating the relationship between SP and climate change, identifying new priorities for research, policy and practice.

Box 1: Recent climate-change projections and scenarios

- According to the IPCC, a 1-in-20 years hottest day is likely to become a 1-in-2 years event by the end of the twenty-first century in most regions, apart from the high latitudes of the Northern hemisphere where it is likely to become a 1-in-5 years event, suggests a projection based on the A1B and A2 emissions scenarios (Lavell et al., 2012). With continued warming, heavy rainfalls associated with tropical cyclones are likely to increase. Projections based on a range of emissions scenarios (B1, A1B, A2) suggest that a 1-in-20 years annual maximum daily precipitation amount is likely to become a 1-in-5 to 1 -in- 15 years event by the end of the century in many regions (ibid.).

- The MIT Joint Program on the Science and Policy of Global Change (2012) projects an additional global mean surface warming above the present of about $1.7^{\circ}$ to $2.9^{\circ} \mathrm{C}$ by 2050 , with a median value of about $2^{\circ} \mathrm{C}$. By 2100 , the range would be $3.5^{\circ}$ to $6.7^{\circ} \mathrm{C}$ with a median of about $4.3^{\circ} \mathrm{C}$.

- Christensen et al. (2011) use three emissions scenarios: a medium-high non-mitigation baseline scenario (A1B); a mitigation scenario (E1), which stabilises global temperature change at about $2^{\circ} \mathrm{C}$ above pre-industrial levels; and a high-emission scenario (RCP8.5). Their projection suggests that under a medium-high emission baseline (A1B), with no mitigation, global average temperatures could rise by between $1.6^{\circ} \mathrm{C}$ and $2.3^{\circ} \mathrm{C}$ by 2041 70 , and $2.4^{\circ} \mathrm{C}$ and $3.4^{\circ} \mathrm{C}$ by $2071-2100$, relative to the modelled baseline period of $1961-$ 90.

- Grinsted et al. (2009) use 4 inversion experiments to relate 2,000 years of global temperatures to sea level and validated model parameters with satellite altimetry. The global mean temperature projections of 6 IPCC AR4 emission scenarios were used to project sea-level rise. Their projection suggests 7" to 23" (18cm to $59 \mathrm{~cm})$, by 2100 .

- Rohling et al. (2008) use paleo-climatic data from the last interglacial period, when global mean temperatures were at least $2^{\circ} \mathrm{C}$ warmer than today and comparable to current projected temperatures, to arrive at a projection which suggests a $63 "(1.6 \mathrm{~m})$ increase in sea level by 2100 .

- Pfeffer et al. (2008) use thermal expansion projected by IPCC AR4 together with kinematic scenarios (for example, varying the velocities of outlet glaciers) to estimate the change in the surface mass balance of ice of Greenland and Antarctica, and the discharge of melting ice sheets and glaciers. They project 31 " to 79 " $(0.785 \mathrm{~m}$ to $2.008 \mathrm{~m})$ by 2100 .

- Jevrejeva et al. (2012) use four new Representative Concentration Pathways (RCP) radiative forcing scenarios to project median sea-level rises. They project 0.57 to $1.10 \mathrm{~m}$ by 2100 , and 1.84 to $5.49 \mathrm{~m}$ by 2500 .

- By 2100 , the likely range for global annual mean temperatures is projected to rise by $2^{\circ}$ to $11.5^{\circ} \mathrm{F}$. The projection is based on the multi-model ensemble results across each of the six Special Report on Emissions Scenarios (SRES) (USGCRP, 2009). 


\section{What's in a name? SP in theory and practice}

SP can be usefully understood as a set of 'public actions taken in response to levels of vulnerability, risk and deprivation which are deemed socially unacceptable within a given polity and society' (Niño-Zarazua et al., 2012: 164, citing Conway et al., 2000). Although it is commonly associated with asset and cash transfers, the concept can include a wide range of inter-related policy fields. The International Labour Organization (cited in Niño-Zarazua et al, 2012), for instance, distinguishes among three different types of SP:

- Social assistance (tax-financed policy instruments aimed at addressing poverty and vulnerability);

- Social insurance (contributory schemes designed to protect workers/dependants from life-course, work-related hazards);

- Labour-market regulation (legal frameworks aimed at ensuring minimum standards of employment and ensuring workers' rights).

By and large, the vast majority of donor-supported SP programmes are social-assistance programmes aimed at providing cash and asset transfers to beneficiaries who meet a particular poverty or vulnerability criterion (Béné, 2011; Davies et al., 2008; Doocy et al., 2006; Farrington and Slater, 2006; Prowse, 2008; Slater et al., 2008; Tanner et al., 2008; Teichman, 2007; Heltberg et al., 2009; Todd et al., 2010; Maluccio, 2010; Wood, 2011; Niño-Zarazua et al., 2012). A key difference between cash and asset transfers concerns the extent to which the transfer in question may be used for productive purposes, as opposed to consumption aimed at meeting immediate 'day-to-day' needs. Cash transfers are often used to address short-term consumption needs in the context of rapid-onset disasters, such as earthquakes, flooding and entitlement failures during droughts. Asset and conditional cash transfers, on the other hand, aim to influence longer-term behaviour by conditioning the transfer of assets or cash in relation to a particular policy outcome, such as nutrition, education and healthcare.

The main attraction of using cash instead of food or asset transfers is that it gives beneficiaries the flexibility and freedom to decide how and when they will invest scarce household resources (Wood, 2011). Extending the freedom to choose puts critical decisions about household needs and investments in the hands of the household, whose members are in theory best placed to assess the needs that are most pressing at a particular point in time (for example, consumption smoothing in order to invest in fodder for livestock). The main drawback, however, is that there is little or no assurance that the cash being transferred will be invested productively, or at all. Partly for this reason, asset and 'conditional cash transfers' (CCTs) have become increasingly popular, especially in the context of programmes that entail long-term behavioural change. CCTs in Mexico, for instance, have been used in programmes such as Oportunidades to encourage household investment in primary education and healthcare (Teichman, 2007; Todd et al., 2010). In essence, the payment of cash is conditional upon the performance of beneficiaries in relation to longterm human-development goals such as investment in childhood education.

Cash and food transfers have been shown to provide a vital safety-net for households whose incomes, assets and livelihoods are negatively affected as a result of rapid-onset events, such as windstorms, flooding and drought (Doocy et al., 2006; Tanner et al., 2009; 
Wood, 2011). When it has worked effectively, for instance, India's food-for-work programme has provided a vital safety-net during food shortages, entitlement failures and famine (Deshingkar et al., 2005). However, CCTs have proved controversial, evoking important policy discussions about the extent to which time-bound social transfers can or should take the place of universal programmes rooted in a system of legislated policy and human rights (see below). Teichman (2007), for instance, has argued that CCTs and cash transfers more generally are at best a limited means of addressing the structural and historical factors that perpetuate poverty and vulnerability to environmental change (more on this below).

A second major form of SP entails the provision of insurance that can transfer the risks of income and asset losses resulting from a variety of environmental and economic shocks. With the growth of microfinance services, micro-insurance programming now provides an important means of insuring against the loss of assets (including inter alia land, housing, livestock, food stocks) and incomes during times of environmental stress (Matin et al., 2008; Heltberg et al, 2009). Within agriculture, one important form of insurance is crop insurance. Whilst insuring against actual crop losses can be costly and prone to corruption (Heltberg et al., 2009), using index-based insurance, which extends coverage in relation to a pre-established index of rainfall or soil moisture allows compensation payments to be made in a more transparent manner (ibid.: 97-8).

The advantage of using index-based insurance is that it reduces the transaction costs of establishing actual losses, thereby improving the ability of insurers to establish eligibility for compensation. However, index-based models also have their limitations. First, they require a reliable means of establishing minimum thresholds, which may exceed the capacity of public and private providers in low-income countries. Second, they fail to cover losses resulting from environmental and other exogenous disturbances that do not meet the minimum threshold (cf. Heltberg et al., 2009: 97). Third, index-based instruments do not necessarily cover losses incurred as a result of lost or devalued labour (Mitchell, 2013). Finally, they create (or at least fail to remove) incentives to live and work in hazardous regions and sectors, which may exacerbate vulnerability over the long term (Heltberg et al., 2009; Mitchell, 2013).

A third and vital form of SP involves the legislation of rights that ensure minimum standards of employment and well-being, such as wages, health and safety regulations and the like. Among many scholars (for example, Chhotray and Hulme, 2008; Niño-Zarazua et al., 2012), such rights-based approaches are advocated on the grounds that they provide a more reliable and legally-enforceable range of entitlements that vulnerable populations can use to obtain access to incomes and employment. However, given the very large degree of informal-sector employment, formal rights and labour codes are often difficult to enforce, raising the importance of governance, social mobilisation, and politics.

Box 2: The limits of insurance

Insurance has an important place in a comprehensive climate risk-management strategy, which must focus on assessing and then reducing risk as a first priority. However, at the moment insurance is simply too prominent, seen by too many governments and agencies as a first move rather than a later consideration. 
Box 2 cont'd

There are a number of problems with an over-reliance on insurance:

(i) Evidence presented in the IPCC 2012 report suggests that insurance is an effective disaster risk-management tool when it is combined with other risk-management measures (for example, early warning, provision of risk information, preparedness and measures to reduce vulnerability). Where it is applied without adequate risk reduction, insurance can convey a feeling of security while actually leaving people excessively exposed to impacts.

(ii) Insurance products never cover the full extent of disaster losses. Intangible losses such as long-term impacts on mental health, lifelong loss of earnings related to missed schooling or malnutrition in drought years, or cultural heritage and identity, are almost uninsurable.

(iii) While there is considerable evidence to suggest that insurance products help with absorbing the financial burden of disasters, there are questions over how long such products will be affordable or even offered by the private sector, given increasing disaster risks and uncertainties, particularly in developing countries. The recent case of a cap on the reinsurance liability in Bangladesh is a case in point. How sustainable, then, is an insurance-dependent approach to risk management for a developing country with rising risks?

(iv) The highest-quality risk assessments are those used by the insurance industry. They are commonly available to governments only at a price and as part of a conversation oriented towards the purchase of an insurance product. A concerted effort is required to maximise the quality of risk assessments available in the public domain. Assessments can then be used to inform a well-thought-through management approach that looks to risk transfer approaches only after implementing a strategy focused on risk reduction.

(v) There has been a lot of work looking at how insurance products can be tailored to those who cannot usually afford to buy insurance, including farmers offering labour to pay premiums or some sort of collective approach to purchasing. However, farmers need to be able to increase their productivity in order to pay the premiums, as offering additional labour time does not come without trade-offs. Even if in-kind payments are accepted, many vulnerable or chronically poor groups, such as the young, elderly and ill, are unable to offer their labour. There has been some interest in the role of SP and safetynets as a way of proactively managing shocks and stresses faced by vulnerable populations and providing a foundation for risk-financing approaches, such as in the case of WFP's relationship to the Productive Safety Net Programme in Ethiopia. While promising, the link between SP and micro-insurance requires further exploration.

(vi) There is insufficient evidence of the medium- and long-term outcomes of the relationships between developing countries, individuals and insurers. Does microinsurance genuinely smooth out the impacts of disasters on poverty? What happens to trust and risk-management approaches when insurers do not deliver as expected? Does insurance lead to increases in risky behaviour and greater exposure? Do insurance schemes perpetuate dependence on post-event pay outs?

Source: Mitchell (2013)

\subsection{Governance, politics and policy}

There is now a large body of scholarship that explores the conditions under which international actors (including donors) can build or undermine the capacity of state and 
non-state actors to formulate policies that may be used to reduce poverty and vulnerability to global environmental change (Birdsall, 2007; Chhotray and Hulme, 2008; de Haan, 2009). ${ }^{2}$ Within the donor community, there is also a strong consensus that the most effective way of incorporating disadvantaged groups into policies that have a bearing on poverty and well-being is to work within existing systems and structures, particularly ones controlled by the state (de Haan, 2009). However, within the climate-change regime, questions have been raised about the ability of the UN Framework Convention on Climate Change (UNFCCC) to provide the institutional conditions under which vulnerable populations may influence or engage in relevant policy processes. Ayers and Huq (2009), for instance, have argued that the National Adaptation Plans of Action (the NAPAs) are exceedingly top-down and technocratic, promoting documents that reflect the priorities of donors, international agencies (especially the Global Environmental Facility) and national governments, as opposed to vulnerable populations.

Geopolitical and bureaucratic realities such as these raise important empirical questions about the conditions under which state and non-state actors can incorporate poor and politically marginal populations into the policy process. As new financial mechanisms are being put in place to support international adaptation, questions are also being raised about the ways in which governments, donors and international institutions can and should prioritise countries, policies and sectors for the purposes of climate-change adaptation. Many of the articles in this issue provide evidence to suggest that beneficiaries were often poorly or inaccurately informed about SP eligibility and benefits, highlighting the importance of incorporating vulnerable populations into SP policy and practice.

But climate change adds a number of factors that complicate the 'standard' ethics and politics of delivering and evaluating SP programmes and policies. One concerns the ethics of requiring current generations to bear the burden of future risks and vulnerabilities (cf. Johnson, 2012). At the heart of the Oportunidades model in Mexico is the idea that the delivery of conditional cash transfers entails an ability on the part of the household to invest in the health and well-being of future generations. To what extent, however, can we expect a single SP programme to reduce the vulnerability of future generations?

A second and related issue concerns the ethics and politics of mobilising resources for social redistribution. Niño-Zarazua et al. (2012) make an important distinction between middle-income country models, in which social transfers are managed by public agencies and embedded in systems of rights and legislated policy, and low-income models that are targeted and largely dependent on international donors. In so doing, they highlight a number of factors that have strong bearing on the nature and sustainability of SP. One is domestic capacity for domestic resource mobilisation. Broadly speaking, countries with larger revenues and revenue-collection capabilities have been able to implement SP policies that are more firmly rooted in a system of domestic legislation and public policy. By the same token, concerns have been raised about the ability of aid-dependent countries with limited revenues and revenue-collection capacities to institutionalise SP programmes that

2. The 2005 Paris Declaration on Aid Effectiveness, for instance, upholds the idea that development reflects the needs and priorities of developing countries. The Accra Accord builds upon these principles by stating that 'country systems' - as opposed to 'donor systems' - 'be used to deliver aid as the first option.' Framed in this way, 'ownership' implies an ability of recipient governments to set the development agenda on their own terms and in relation to their own priorities. 'Alignment', on the other hand, implies that donors are willing and able to align their policy priorities with those of recipient countries (de Haan, 2009). 
are embedded in a system of rights and policy legislation (Teichman, 2007; Niño-Zarazua et al., 2012).

Although middle-income models have offered new programmes with universal coverage (for example, the National Rural Employment Guarantee Act in India), lowincome countries (such as Zambia, Malawi, Mozambique, Bangladesh) tend to be more substantially targeted on the basis of household incomes, dependency ratios and other poverty criteria. Empirical studies of SP in India, Mexico and Nicaragua have shown that institutional capacity to deliver targeted cash and conditional cash-transfer programmes is highly dependent upon the capabilities and resources that implementing agencies have at their disposal (Deshingkar et al., 2005; Maluccio, 2010; Todd et al., 2010), raising questions about institutional capacity and governance. The history of Western welfare-state formation suggests that ambitious social-welfare policies emerged as a result of important historical movements aimed at securing universal labour rights, income guarantees and other social benefits (Esping-Andersen, 1990). Whether donors can influence the kinds of mobilisation that would lead to more institutionalised forms of SP depends in large part on the nature of the aid relationship, including especially the extent to which donors are able to support state capacity to mobilise domestic resources, enact legislation and implement policy (Birdsall, 2007; de Haan, 2009).

\section{Addressing the climate challenge: understanding the role of SP}

This theme issue addresses four themes that have direct bearing on the ways in which donors, researchers and development practitioners understand, design and evaluate SP policies for the purposes of climate-change adaptation. One is the impact of SP on household investment in assets, livelihoods and livelihood diversification. SP programmes often provide income and/or assets (for example, livestock) sometimes in a 'lumpy' form (such as stipends and subsidies for vaccinations). However, assuming that climate change will entail shocks that affect the economic and ecological productivity of entire regions, sectors and livelihood systems, questions can be raised about the viability and desirability of supporting conventional (and largely sedentary) livelihood strategies. Are SP programmes, for instance, building livelihoods that are more or less dependent upon climate-sensitive resources, sectors and environmental services? What kinds of assets, for instance, are most appropriate and effective in supporting long-term adaptation? To what extent and in what form can SP policies support populations displaced by climate change?

On this theme, Panda's analysis of SP in India (this volume) found that access to crop insurance encouraged farmers to delay their planting until conditions were more favourable, suggesting that insurance can provide an important means of managing and mitigating risk during unfavourable climatic conditions. At the same time, the study found that farmers with crop insurance were more likely to invest in commercial crops, such as cotton, as opposed to more traditional varieties of paddy. To the extent that a diversity of livelihood and income streams can build the resilience of rural/agricultural households to future climatic hazards and shocks (such as disease or drought), the decision to invest in a single variety of cotton suggests an incentive structure that may well exacerbate future vulnerability to climatic change. Similarly, Weldegebriel and Prowse's study (this volume) found that access to the Productive Safety Net Programme (PSNP) in Ethiopia did not 
increase farm or non-farm income, but instead increased the sale of natural resources (viewed as a negative adaptation strategy).

Such findings highlight the importance of identifying the activities, sectors and regions that are expected to suffer as a result of climate change (cf. Kuriakose et al., this volume). However, climate change consists of a number of factors (for example, uncertainty about micro-climatic impacts and timelines) that make it difficult if not impossible to assign probabilities to particular negative outcomes and events, and to establish whether and to what extent current investments - in assets or infrastructure - will be prone to future climatic change. ${ }^{3}$ During India's drought in 2012, for instance, meteorologists had little or no indication that the monsoons were about to fail, and the Meteorological Department was unable to 'adequately explain the complexities of its climate models, which led observers to believe rainfall was projected to be normal', (Eshelman and ClimateWire, 2012). Here it is worth noting that these are relatively shortrun projections in a country that has relatively strong capacity for undertaking and disseminating meteorological data.

A second and related theme concerns the ways in which we understand and assess SP and adaptation for the purposes of planning, implementation and evaluation. Assuming SP will alter and expand the range of adaptation strategies vulnerable populations have at their disposal, how should we evaluate the aims and impacts of adaptation and development programming? For instance, what is an appropriate timeline for evaluating the impact of SP? To what extent and in what ways can inter-generational timelines used by the IPCC be incorporated into SP policy and evaluation?

As Sabates-Wheeler and Devereux (2010: 274) have argued, conventional cashtransfer programmes often fail to compensate for the loss of incomes and assets that result from 'price inflation, seasonal cycles or "price spikes". Innovative programmes have been shown to combine locally indexed food and cash transfers to mitigate the risk of shortfalls. However, climate change raises difficult questions about the timelines we use to evaluate effectiveness and impact over the long term (i.e. beyond the cycle of deprivation that follows a major climatic event). If, for instance, cash and asset transfers are able to prevent famine in the short run by investing in rain-fed agriculture, to what extent are these investments making beneficiaries more or less vulnerable to future climatic change? And to what extent is it reasonable to evaluate them on the basis of inter-generational vulnerability to climate change? If so, which indicators should we use?

A number of studies (for example, Weldegebriel and Prowse, this volume; Panda, this volume) use agricultural investment and livelihood diversification as proxies for understanding future vulnerability to climate change. Weldegebriel and Prowse, for instance, use changes in farm, non-farm and off-farm income as proxies for neutral, positive and negative adaptation. Leaving for now the role that agriculture can and should play in future climate-resilient development models (Section 4), the methodology provides

3. The IPCC (Nicholls et al., 2007), for instance, projects with 'very high confidence' (which equates to a 9-in-10 chance of being correct) that coastal areas will become increasingly vulnerable to 'an accelerated rise' in eustatic sea levels, ranging from 0.2 to 0.6 metres or more by 2100 . However, the models on which these projections are made do not assign probabilities to precise times and locations, making it very difficult to calculate the costs and benefits of future expected value. Risk in this instance may be usefully defined as a condition under which it is possible to assign probabilities to negative outcomes. Uncertainty, on the other hand, implies that probabilities are effectively unknown (cf. Sunstein, 2007; Gardiner, 2010). 
a useful and replicable set of indicators that can be used in future evaluations of SP and climate change.

To what extent, however, can positive or negative vulnerability outcomes be attributed to a particular policy or programme? If we assume that vulnerability implies exposure to hazards that undermine the ability to adapt (Smit and Wandel, 2006; Adger, 2006; Fussel, 2007), asset and cash transfers are but one of many factors that have a bearing on a household's ability to manage vulnerability over time. Weldegebriel and Prowse (this volume) use propensity score matching as a means of comparing beneficiary and nonbeneficiary households in rural Ethiopia. Due to the limitations of the dataset they utilised, their ability to establish causal claims is strongly circumscribed. That said, their article identifies useful indicators for adaptation and a future research terrain on the extent to which social protection influences smallholders' autonomous adaptation strategies.

Others (also including Panda; Coirolo et al.) use qualitative interviews with beneficiaries and non-beneficiaries as a means of understanding and illustrating the impact of the programme in question. Bearing in mind the challenges of interpreting personalimpact statements and surveys, such methods are particularly useful in documenting the ways in which SP policies are being implemented on the ground, highlighting important insights about the logistical challenges of targeting and reaching intended beneficiaries. The articles by Panda and Coirolo et al., for instance, provide qualitative evidence that information about eligibility and access to SP programming was poorly communicated among beneficiaries and members of the local community, highlighting important lessons for future policy (see below).

A final and crucial theme concerns the sustainability and governance of SP programmes aimed at reducing poverty and vulnerability to future climatic change. Recent empirical work on the long-term impact of SP programming has shown that countries with capable bureaucracies and legal systems that recognise the rights of vulnerable populations to socialised benefits, such as pensions, housing and food (for example, India), are better able to support livelihoods that are sustainable and resilient to periods of severe environmental stress (for example, Niño-Zarazua et al., 2012). Conversely, countries that lack the ability to mobilise domestic public resources are often highly dependent on ad-hoc aid transfers, raising important questions about the ways in which donors and development institutions are effective in making SP policies more reliable, predictable and effective for poor and marginal populations.

But what does this mean in the context of climate change? Like many aspects of climate policy, the ability of planners and policy-makers to incorporate climate change into SP policy is constrained by the uncertainties of how, when and where climate change will manifest itself and the limited timelines of budgets, electoral cycles and the like. As new financial mechanisms are being put in place to support international adaptation, are the ways in which governments, donors and NGOs are institutionalising SP conducive to increasing resilience? What are the institutional challenges of targeting and reaching the most vulnerable? What kinds of policies need to be in place to build resilience and sustainability over the next century?

Coirolo et al.'s study of SP programming in Bangladesh suggests that the Government of Bangladesh has been able to devise a number of policies (such as food for work, the social safety-net programme and the vulnerable group development programme) that have been instrumental in helping poor and vulnerable populations prepare for and recover from 
extreme climatic events, such as seasonal flooding. However, the ability of these and other programmes to reach low-income communities and households in a timely manner is still constrained by a number of political/institutional factors. First, the budgetary system in Bangladesh is structured in such a way that the majority of SP funds are released during the peak periods of agricultural demand, as opposed to the lean 'monga' season, during which income-earning opportunities are most scarce. Second, the government uses a national poverty line that fails to take account of important regional variations in income, livelihood and inequality. Finally, the research documents a number of 'exclusion and inclusion errors' in which a very small percentage of eligible households were able to access SP benefits, while a large number of ineligible households received benefits.

Bangladesh is not, of course, alone in this regard. Indeed, the empirical literature is replete with examples of political and institutional systems that routinely misallocate and misappropriate resources aimed at improving the lives of the poor (see Deshingkar et al., 2005; Chhotray and Hulme, 2008; Devereux, 2009; Sabates-Wheeler and Devereux, 2010; Niño-Zarazua et al., 2012). The key point is that effective redistributive SP programmes require an ability on the part of governments and NGOs to invest in public goods that will build resilience through insurance (Panda, this volume), safety-nets (Coirolo et al; Weldegebriel and Prowse, this volume) and substantive efforts to mainstream climate change into development policy (Kuriakose et al., this volume).

Another issue relates to scale. On this issue, Kuriakose et al. (this volume) identify a number of guidelines that may be used to improve the co-ordination of agencies involved in 'climate-responsive' SP programming. Many of these (for example, replacing ad hoc emergency funding with regular, ex ante financing; incorporating disaster risk reduction into development policy and practice) are part of what now constitutes best donor practice (cf. de Haan, 2009). But there are a number of others that challenge the conventional ways in which vulnerable populations are typically targeted for the purposes of SP. One, for instance, concerns the challenge of targeting and supporting populations that are likely to be physically displaced by the effects of climate change:

When policy-makers decide to maintain households in regions where old livelihood strategies are no longer viable - for example, by providing safety-nets, subsidies, or other support - they need to consider the counter-case: that is, is the support policy in fact promoting long-term dependence in irreversibly degraded environments? In places where, for instance, desertification has taken over farmland or where melting permafrost has changed the ecology of rangelands, livelihoods may be changed permanently, possibly beyond the scope of any adaptation strategy. (Kuriakose et al., this volume: o26)

For populations facing the prospect of permanent displacement, SP may provide an important means of supporting 'economic' as opposed to 'distress' migration in advance of catastrophic climate change (cf. Johnson and Krishnamurthy, 2010).

A final issue concerns the challenge of incorporating long-range forecasting into existing plans and budgets. In theory, consolidating ad hoc approaches to humanitarian assistance into a regular and reliable system of national SP policies may well improve the co-ordination of agencies in line with contemporary best practice, but will it actually lead to 
cost savings for governments and donors (cf. Kuriakose et al., this volume)? And again, what timeline should we use in making this assessment?

At the end of the day, the articles in this issue probably raise more questions than they answer. Taken together, they provide a number of important theoretical, methodological and empirical insights about the possibilities of using SP to reduce poverty and vulnerability to climate change, highlighting the need for further research on the ways in which donors, governments and societies more generally may incorporate climate-change vulnerabilities into SP policy and practice. The following section identifies a number of priorities for research, policy and practice.

\section{Implications for research, policy and practice}

There is now a growing consensus that climate change poses serious threats to existing development policies and investments in a wide variety of policy fields, including health, agriculture and insurance (Klein et al., 2007; Boyd et al., 2009; Brooks et al., 2009; Lavell et al., 2012). Incorporating climate change into existing policy has therefore become a pressing priority. However, identifying the particular modes and means by which governments, donors and NGOs may 'climate-proof' future policies and investments is still poorly understood (Klein et al., 2007; UNDP, 2008; Boyd et al., 2009; Brooks et al., 2009; World Bank, 2010).

This Special Issue presents a number of empirical and theoretical insights into the ways in which governments, donors and societies more generally may use SP programming to reduce poverty and vulnerability to climate change. Principal among these are the important ways in which asset and cash transfers can help impoverished households prepare for and recover from a variety of extreme climatic events, such as windstorms and drought. The articles also provide a range of indicators that may be used in future empirical studies of SP and climate change. Weldegebriel and Prowse's framework suggests that investments of time, labour and assets in farm, non-farm and off-farm activities may be used as proxies for evaluating household adaptation. Similarly, and more squarely oriented towards donor policy and practice, Kuriakose and colleagues identify a number of climate-responsive indicators that may be used in developing and evaluating SP policy and programming.

That said, a great deal of evidence being presented in this volume is based on crosssectional data, highlighting the need for more robust indicators and methodologies that can be used to evaluate the impact of SP programmes over longer and potentially intergenerational periods of time. A number of priorities can be highlighted. One is a need for longitudinal studies that capture the historical ways in which SP beneficiaries have invested in assets, livelihoods and capabilities over time (i.e. after the programme or disaster in question). A second is the need for better baselines that can be used to monitor and evaluate impact over time. Mexico's Oportunidades and Ethiopia's PSNP are examples of programmes that have been exceptionally well-documented in the research and policy literature. However, many others have not been documented or evaluated to the same degree, highlighting the need to invest in the documentation and evaluation of SP programmes and policies. Third, there is a need to incorporate climate science and modelling into future SP programming and evaluation. However, the models on which these projections are made do not assign probabilities to precise times and locations, 
making it very difficult to say how and where climate change will manifest itself in specific localities.

Coming back to policy, questions can also be raised about the kinds of livelihoods (and vulnerabilities) that are being promoted as a result of SP. A number of articles make the case that diversification away from agriculture and natural-resource-based livelihoods may provide a useful way of spreading risk in relation to climate change. Weldegebriel and Prowse, Panda and Coirolo et al., for instance, all suggest that investment in certain forms of agriculture may in fact exacerbate vulnerability to future climatic change, raising difficult questions about whether and to what extent development policy can or should be encouraging diversification away from livelihoods that are dependent upon climatesensitive sectors and regions, such as forestry, fishing and sedentary agriculture. Questions can also be raised about the extent to which existing SP policies are producing higher carbon emissions through the promotion of industrial forestry and farming (cf. Panda, this volume).

To the extent that investment in a single sector or variety increases exposure to future climatic shocks and stresses, diversity and diversification may well be worth promoting. That said, the potential gains of spreading risk through diversification need to be weighed in relation to the opportunity costs of divesting from high-return crops and commodities and the benefits of investing in other risk transfer programmes, such as crop- or indexbased insurance (cf. Heltberg et al., 2009; Kuriakose et al., this volume). Moreover, the notion that maintaining a diversity that is rooted in 'traditional' varieties appears to preclude the application of new (potentially drought- or flood-resistant) varieties, including, conceivably, ones developed through non-conventional breeding techniques (cf. Godfray et al., 2010). As Weldegebriel and Prowse conclude, incorporating climate change into SP programming will entail 'a focus on transforming productive livelihoods along with protecting, and adapting to changing climate conditions as opposed to merely reinforcing coping mechanisms'.

A related issue concerns the challenge of targeting. Coirolo and colleagues highlight the challenges of identifying and reaching vulnerable populations in a timely manner. Devising a system that takes account of the seasonality and regionality of poverty and vulnerability will be essential in improving the ability of SP programmes to target the poorest and most vulnerable. However, targeting on the basis of projected regional patterns of climatic vulnerability requires extensive information about labour, poverty and longrange meteorology, highlighting the need for extensive collaboration across a variety of policy fields (cf. Kuriakose et al., this volume).

At the end of the day, asset- and cash-transfer programmes are micro-economic interventions aimed at influencing household decisions about time, labour and money. Whether or not they have multiplier effects that enhance the resilience of community-based assets (for example, cyclone shelters, emergency funds, investments in disaster-risk reduction), it is unlikely that SP policies will on their own be able to address the complexities of climate change, thus highlighting the need to develop synergies between SP programming and other policy fields, such as health, education and disaster-risk reduction.

It goes without saying that formulating policies that can address the material, psychological and political costs of climate change will transcend the abilities of any single programme or agency. The vast majority of policies being documented in this volume are ones that protect and invest in 'productive' sectors, primarily agriculture. Developing 
policies that can address the multi-level, inter-generational nature of climate change will entail strategic thinking about the ways in which conventional SP instruments (for example, pensions, disability insurance) may be used to manage the risk of future climatic change. Towards this end, the preceding analysis has identified a number of short- and long-range policies that may be used to build assets, reduce vulnerability and pool risk.

first submitted September 2012 final revision accepted May 2013

\section{References}

Adger, W.N. (2006) 'Vulnerability', Global Environmental Change 16(3): 268-81.

Awokuse, T.O. (2011) 'Food Aid Impacts on Recipient Developing Countries: A review of empirical methods and evidence', Journal of International Development 23(4): 493514.

Ayers, J. and Huq, S. (2009) 'Supporting Adaptation to Climate Change: What role for development assistance?' Development Policy Review 27(6): 657-92.

Barrientos, A. and Niño-Zarazua, M. (2010) Do Social Protection Programmes have LongTerm Effects on Poverty Reduction? Lessons from Mexico's Oportunidades and challenges ahead. Policy Brief No. 20. Manchester: Chronic Poverty Research Centre.

Béné, C. (2011) 'Social Protection and Climate Change', IDS Bulletin 42(6): 67-70.

Birdsall, N. (2007) 'Do No Harm: Aid, weak institutions and the missing middle in Africa', Development Policy Review 25(5): 575-98.

Boyd, E.; Grist, N.; Juhola, S. and Nelson, V. (2009) 'Exploring Development Futures in a Changing Climate: Frontiers for Development Policy and Practice,' Development Policy Review 27(6): 659-74.

Brooks, N., Grist, N. and Brown, K. (2009) 'Development Futures in the Context of Climate Change: Challenging the present and learning from the past,' Development Policy Review 27(6): 741-65.

Chhotray, V. and Hulme, D. (2008) 'Contrasting Visions for Aid and Governance in the 21st Century: The White House Millennium Challenge Account and DFID's Drivers of Change,' World Development 37(1): 36-49.

Christensen, O.B.; Goodess, C.M.; Harris, I. and Watkiss, P. (2011) 'European and Global Climate Change Projections: Discussion of climate change model outputs, scenarios and uncertainty in the EC RTD ClimateCost Project', in P. Watkiss (ed.), The ClimateCost Project. Final Report. Volume 1: Europe. Stockholm: Stockholm Environment Institute.

Conway, T., de Haan, A. and Norton, A. (eds) (2000) Social Protection: New directions of donor agencies. London: Department for International Development.

Davies, M.; Oswald, K.; Mitchell, T. and Tanner, T. (2008) Climate Change Adaptation, Disaster Risk Reduction and Social Protection. Briefing Note. Brighton: Institute of Development Studies.

de Haan, Arjan (2009) How the Aid Industry Works: An introduction to international development. Sterling, VA: Kumarian Press. 
Deshingkar, P., Johnson, C. and Farrington, J. (2005) 'State Transfers to the Poor and Back: The case of the Food for Work Program in India', World Development 33(4): 575-91.

Devereux, S. (2009) 'Why Does Famine Persist in Africa?', Food Security 1(1): 25-35.

Devereux, S. and Sabates-Wheeler, R. (2004) Transformative Social Protection. IDS Working Paper 232. Brighton: : Institute of Development Studies.

Doocy, S.; Gabriel, M.; Collins, S.; Robinson, C. and Stevenson, P. (2006) 'Implementing Cash for Work Programmes in Post-Tsunami Aceh: Experiences and lessons learned', Disasters 30(3): 277-96.

Eshelman, R.S. and ClimateWire (2012) 'India's Drought Highlights Challenges of Climate Change Adaptation', Scientific American 3, August 2. http://www.scientificamerican. com/article.cfm?id=indias-drought-highlights-challenges-climate-change-adaptation

Esping-Andersen, G. (1990) The Three Worlds of Welfare Capitalism. Princeton, NJ: Princeton University Press.

Farrington, J. and Slater, R. (2006) 'Cash Transfers: Panacea for poverty reduction or money down the drain?', Development Policy Review 24(5): 499-511.

Fussel, H-M. (2007) 'Vulnerability: A generally applicable conceptual framework for climate change research', Global Environmental Change 17(2): 155-67.

Gardiner, S. (2010) 'Ethics and Global Climate Change', in S. Gardiner; S. Caney; D. Jamieson and H. Shue (eds), Climate Ethics: Essential readings. Oxford: Oxford University Press.

Godfray, H.; Charles J.; John R.; Beddington, Ian; Crute, R.; Haddad, Lawrence; Lawrence, David; Muir, James F.; Pretty, Jules; Robinson, Sherman; Thomas, Sandy M.; Toulmin, Camilla (2010) 'Food Security: The challenge of feeding 9 billion people', Science 327(5967): 812-18.

Grinsted, A., Moore, J.C. and Jevrejeva, S. (2009) 'Reconstructing Sea Level from Paleo and Projected Temperatures 200 to 2100 AD', Climate Dynamics 34(4): 461-72.

Heltberg, R., Siegel, P.B. and Jorgensen, S.L. (2009) 'Addressing Human Vulnerability to Climate Change: Toward a 'no-regrets' approach', Global Environmental Change 19(1): 89-99.

IPCC (2012) Managing the Risks of Extreme Events and Disasters to Advance Climate Change Adaptation. Cambridge: Cambridge University Press.

Jevrejeva, S., Moore, J.C. and Grinsted, A. (2012). 'Sea Level Projections to AD 2500 with a New Generation of Climate Change Scenarios', Global and Planetary Change 8081: $14-20$.

Johnson, Craig (2012) 'Governing Climate Displacement: The ethics and politics of human resettlement', Environmental Politics 21(2): 308-28.

Johnson, C. and Krishnamurthy, K. (2010) 'Dealing with Displacement: Can 'social protection' facilitate long-term adaptation to climate change?', Global Environmental Change 20(4): 648-55.

Klein, R. et al. (2007) 'Portfolio Screening to Support the Mainstreaming of Adaptation to Climate Change into Development Assistance', Climatic Change 84(1): 23-44.

Lavell, A.; Oppenheimer, M.; Diop, C.; Hess, J.; Lempert, R.; Li, J.; Muir-Wood, R. and Myeong, S. (2012) 'Climate Change: New dimensions in disaster risk, exposure, vulnerability, and resilience', in C.B. Field et al. (eds), Managing the Risks of Extreme Events and Disasters to Advance Climate Change Adaptation. A special report of 
Working Groups I and II of the Intergovernmental Panel on Climate Change (IPCC). Cambridge and New York: Cambridge University Press.

Maluccio, J.A. (2010) 'The Impact of Conditional Cash Transfers on Consumption and Investment in Nicaragua', Journal of Development Studies 46(1): 14-38.

Matin, I. et al. (2008) Crafting a Graduation Pathway for the Ultra Poor: Lessons and evidence from a BRAC programme. Working Paper 109. Manchester: Chronic Poverty Research Centre.

MIT Joint Program on the Science and Policy of Global Change (2012) 2012 Energy and Climate Outlook. Cambridge, MA: Massachusetts Institute of Technology. Available online at http://globalchange.mit.edu/files/document/MITJPSPGC-Outlook2012.pdf

Mitchell, T. (2013) 'Seduced by Disaster Insurance? Don't dive in'. London: Climate and Development Knowledge Network. http://cdkn.org/2012/06/seduced-by-disasterinsurance-dont-dive-in/

Nicholls, R.J.; Wong, P.P.; Burkett, V.R.; Codignotto, J.O.; Hay, J.E.; McLean, R.F.; Ragoonaden, S. and Woodroffe, C.D. (2007) 'Coastal Systems and Low-Lying Areas', in M.L. Parry et al (eds), Climate Change 2007: Impacts, adaptation and vulnerability. Contribution of Working Group II to the Fourth Assessment Report of the Intergovernmental Panel on Climate Change. Cambridge: Cambridge University Press.

Niño-Zarazúa, M.; Barrientos, A.; Hickey, S. and Hulme, D. (2012) 'Social Protection in Sub-Saharan Africa: Getting the politics right', World Development 40(1): 163-76.

Parry, M.L.; Canziani, O.F.; Palutikof, J.; van der Linden, P. and Hanson, C. (2007) Climate Change 2007: Impacts, adaptation and vulnerability. Contribution of Working Group II to the Fourth Assessment Report of the Intergovernmental Panel on Climate Change. Cambridge: Cambridge University Press.

Pfeffer, W.T., Harper, J.T. and O'Neel, S. (2008) 'Kinematic Constraints on Glacier Contributions to 21st-Century Sea-Level Rise', Science 321(5894): 1340-43.

Prowse, M. (2008) Pro-Poor Adaptation: The role of assets. ODI Opinion No. 117. London: Overseas Development Institute.

Prowse, M., Grist, N. and Sourang, C. (2009) Closing the Gap Between Climate Adaptation and Poverty Reduction Frameworks. Project Briefing 21. London : Overseas Development Institute.

Rohling, E.J.; Grant, K.; Hemleben, C.H.; Siddall, M.; Hoogakker, B.A.A.; Bolshaw, M. and Kucera, M. (2008) 'High Rates of Sea-Level Rise During the Last Interglacial Period', Nature Geoscience 1: 38-42.

Sabates-Wheeler, R. and Devereux, S. (2010) 'Cash Transfers and High Food Prices: Explaining outcomes of Ethiopia's Productive Safety Net Programme', Food Policy 35(4): 274-85.

Sabates-Wheeler, R. and Devereux, S. (2007) 'Social Protection for Transformation', Development 38(3): 23-8.

Slater, R., Farrington, J. and Holmes, R. (2008) A Conceptual Framework for Understanding the Role of Cash Transfers in Social Protection. Project Briefing No. 5. London: Overseas Development Institute.

Smit, B. and Wandel, J. (2006) 'Adaptation, Adaptive Capacity and Vulnerability', Global Environmental Change 16(3): 282-92. 
Sunstein, C. (2007) 'The Catastrophic Harm Precautionary Principle', Issues in Legal Scholarship Article 3: 1-29.

Tanner, T.; Mitchell, T.; Polack, E. and Guenther, B. (2009) Urban Governance for Adaptation: Assessing climate change resilience in ten Asian cities. Working Paper 315. Brighton: Institute of Development Studies.

Teichman, J. (2007) 'Redistributive Conflict and Social Policy in Latin America', World Development 36(3): 446-60.

Todd, J.E. et al. (2010) 'Conditional Cash Transfers and Agricultural Production: Lessons from the Oportunidades experience in Mexico', Journal of Development Studies 46(1): 39-67.

UNDP (2008) Human Development Report 2008: Fighting climate change: Human solidarity in a divided world. New York: United Nations Development Programme.

US Global Change Research Program (USGCRP) (2009) Global Climate Change Impacts in the United States. Cambridge: Cambridge University Press.

Wood, R.G. (2011) 'Is there a Role for Cash Transfers in Climate Change Adaptation?', IDS Bulletin 42(6): 79-85.

World Bank (2010) World Development Report 2010: Development and Climate Change. Washington, DC: World Bank. 